\title{
Credit, Capital Flows and Monetary Policy: A Post-Keynesian Analysisa
}

\author{
NAZIM KADRI EKINCI ${ }^{\mathrm{b}}$
}

Received: 11.06.2018; Revised: 19.10.2018; Accepted: 02.11.2018

\begin{abstract}
The credit channel literature implicitly relies on the fact that capital spending depends on financing and that credit is the main form of financing. The mainstream model tries to avoid this implication by recourse to artificial concepts and variables such as the "external finance" premium. We, by contrast, explicitly model capital expenditures as a function of the credit volume along with other relevant variables. This formulation has roots in the Post-Keynesian logico-temporal ordering of finance, production and the realisation of income. The inclusion of credit in expenditure functions result in a simple income determination model making the roles of credit and monetary policy transparent. A financial block is added to the model to determine the interest rates and credit aggregates. Principles of consistent macro modelling on Post-Keynesian principles are carefully delineated. In particular, the principle of Keynesian dichotomy and the necessity of an appropriate lead-lag structure in simultaneous equation models compatible with the Keynesian logico-temporal ordering is stressed. An example demonstrates the model's ability in generating a reasonable account of possible outcomes in response to an exogenous shock.
\end{abstract}

JEL codes: E12, E52, F32

Keywords: Credit Channel, Capital Inflows, Monetary Policy, Post-Keynesian Modelling

\section{Introduction}

Monetary policy transmission mechanism remains to be a black box (Bernanke \& Gertler, 1995). The basic mechanism in an open economy, as in the Mundell-Fleming model, relies on monetary policy-induced changes in interest and exchange rates. However, a cursory glance at the website of any central bank will reveal a much more complex mechanism in the form of a flowchart, elaborating how changes in policy rates end up affecting the rate of inflation. And somewhere in these flowcharts there is usually a mention of "credit". According to the $\mathrm{ECB}$, for example, "... higher interest rates increase the risk of borrowers being unable to pay back their loans. Banks may cut back on the amount of funds they lend to households and firms. This may also reduce the consumption and investment by households and firms

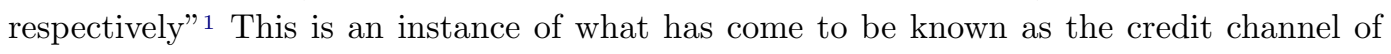
monetary policy transmission.

${ }^{a}$ Helpful suggestions by two anonymous referees are gratefully acknowledged.

b Department of Economics and Finance, University of Kurdistan Hêwler, Erbil, Iraq. e-mail: nkekinci@ukh.edu.krd

${ }^{1}$ https://www.ecb.europa.eu/mopo/intro/transmission/html/index.en.html 
In the mainstream or neoclassical model, macroeconomic adjustment works through relative prices. For the monetary transmission mechanism, the crucial relative price is the neoclassical cost of capital (Bernanke \& Gertler, 1995). Thus "...monetary policymakers use their leverage over short-term interest rates to influence the cost of capital and, consequently, spending on durable goods, such as fixed investment, housing, inventories and consumer durables." However, they note that in much of the empirical work "...the most common finding is that nonneoclassical factors-for example, "accelerator" variables such as lagged output, sales or cash flow-have the greatest impact on spending." (Bernanke \& Gertler, 1995, 27-28). The broad credit channel mechanism that they elaborate is an explanation of this apparent anomaly. The critical variable in this mechanism, in the spirit of neoclassical adjustment through relative prices, is another relative price, the "external finance premium". This is defined to be the difference between the cost of internal funds (borrowing from oneself) and funds obtained through externally borrowing, resulting from capital market imperfections or frictions. Changes in policy rates result in changes in this premium in the same direction. "Because of this additional effect of policy on the external finance premium, the impact of monetary policy on the cost of borrowing broadly defined and, consequently, on real spending and real activity-is magnified." Their credit channel mechanism is essentially an explanation of how and why monetary policy may affect this premium. They propose two lines of explanation. "The first of these, the balance sheet channel, stresses the potential impact of changes in monetary policy on borrowers' balance sheets and income statements, including variables such as borrowers' net worth, cash flow and liquid assets. The second linkage, the bank lending channel, focuses more narrowly on the possible effect of monetary policy actions on the supply of loans by depository institutions" (Bernanke \& Gertler, 1995, 29).

The crucial aspect of their analysis for our purposes is contained in the following: "...the incorrect premise that ... treats ... credit aggregates as an independent causal factor affecting the economy. Except in rare circumstances, credit is not a primitive driving force; rather, credit conditions -best measured, by the way, by the external finance premium and not the aggregate quantity of credit- are an endogenous factor that help shape the dynamic response of the economy to shifts in monetary policy." (Bernanke \& Gertler, 1995, 43)

On the contrary, one of the premises of this study is exactly that credit aggregates are independent causal factors affecting spending, especially capital spending of consumers (housing and durables) and firms (investment). The argument in the above quotation from Bernanke and Gertler is based on the premise that capital spending requires saving. The basic premise of Keynesian macroeconomics is contained in the following:

"The ex-ante saver has no cash, but it is cash which the ex-ante investor requires. On the contrary, the finance required during the interregnum between the intention to invest and its achievement is mainly supplied by specialists, in particular by the banks, which organise and manage a revolving fund of liquid finance. For 'finance' is essentially a revolving fund. It employs no savings.

... The investment market can become congested through shortage of cash. It can never become congested through shortage of saving. This is the most fundamental of my conclusions within this field." (Keynes, 1937, 666-668) 
This implies a causality nexus running from financing (credit) to investment (in capital assets and working capital) and to saving. Recently Borio and Disyatat (2015), arguing from a broadly neoclassical perspective, have forcefully argued that capital expenditures require financing, not saving. Their analysis contains important insights in an open economy context as considered below. Thus, in the Post-Keynesian framework investment makes saving. Associated with this is the Post-Keynesian endogenous money theory whereby credits make deposits ${ }^{2}$. Endogeneity is a relative concept. In the Post-Keynesian literature money is, foremost, endogenous with respect production in that production starts with loans from banks to finance working capital. "Money is introduced into the economy through the productive activities of firms, as these activities generate income. There can be no money without production" Lavoie $(1984,774)$. And the idea that investment cannot be constrained by saving follows from the simple fact that "... no saving can appear without income being distributed, and no income can be distributed without entrepreneurs getting into debt" (Lavoie, 1984, 775).

This argument must be complemented. When entrepreneurs get into debt they can pay out wages. To be able to distribute the non-wage income, the main source of saving, the part of the output that corresponds to capital expenditures must be sold so that non-wage income is realised, distributed and saved. We see that the logico-temporal ordering of income generation and realisation points to the necessity of financing of capital expenditures through the second round of credit generation. This is in effect the point made by Keynes in the above quotation. The neoclassical model cannot capture such an ordering and the associated role of money and credit that it entails because in the model everything happens simultaneously in an auction setting where agents make decisions on output not yet produced based on incomes not yet received. During the auction, decisions are reconciled through relative price adjustments and the model's envisagement of production and distribution essentially ends at this point.

Whether credit expansion and money creation are also endogenous with respect to the financing of capital expenditures, without affecting capital spending decisions, is a subtler issue. The Post-Keynesian literature acknowledges the phenomenon of credit rationing, albeit through an entirely different mechanism as exemplified in Wolfson (1996). Accordingly, "...bankers accommodate all creditworthy demands for credit, and ration all those demands not deemed creditworthy" (Wolfson, 1996, 455). But then the issue of how banks determine "creditworthiness" becomes important and New-Keynesian themes of balance-sheet and credit channel reappear in the Post-Keynesian arguments, "with different reasoning" (Rochon and Rossi $(2007,544)$, for example). Important clues are contained in what Keynes had to say on banks' ability to influence capital spending?:

"If ... the lending of money takes place according to the principles of a perfect market, ... given the demand-schedule of borrowers, the effective bank-rate and bond-rate must uniquely determine the production of capital-goods and ... the volume of investment. So far, however, as bank loans are concerned, lending does not - in Great Britain at least - take place according to the principles of a perfect market. There is apt to be an unsatisfied fringe of borrowers, the size

2 See Lavoie (1984) on both points.

${ }^{3}$ See also Wolfson (1996, 448-449). 
of which can be expanded or contracted, so that banks can influence the volume of investment by expanding or contracting the volume of their loans, without there being necessarily any change in the level of bank-rate, in the demandschedule of borrowers, or in the volume of lending otherwise than through the banks" (Keynes, 1930, 212). ${ }^{4}$

Accordingly, changes in the volume of credit affect investment in the same direction, and the volume of credit can be changed by banks irrespective of interest rates. On this view, the credit and associated channels of monetary transmission essentially rely on the effects of central bank actions on the volume of bank loans and the "size of the unsatisfied fringe of borrowers".

In the next section, these arguments are pulled together in a simple model of income determination in which the volume of credit is a determinant of capital expenditures. The model provides a plausible interpretation of the various channels of monetary transmission that go under the name of the credit channel. In the third section, the model is extended to an open economy. The role of capital inflows in relieving liquidity constraints and credit expansion is discussed. In Section 4 price and exchange rate dynamics are introduced to obtain a reasonably complete model. An example in comparative analysis illustrates the workings of the model. A final section concludes.

\section{A Framework of Analysis}

As argued above, the Post-Keynesian framework implies financing at two stages of income generation. First, when output is produced credit is necessary to finance working capital so that wages can be paid. Second, financing is necessary for capital (consumer durables and investment goods) expenditures so that non-wage income can be realised. Producers embark upon production with the expectation of forthcoming demand, and credit generation at this stage is, as is standard in the Post-Keynesian literature, demand determined and is fully accommodated under prevailing conditions. We therefore, do not explicitly model the first stage of credit creation. Capital expenditures are part of the (expected) effective demand and output is demand determined according to

$$
Y=C(\underset{+}{Y})+C E\left(\underset{+}{Y}, \underset{+}{r}, L_{C}\right)+I\left(\underline{r}_{+}, L_{I}\right)+G+N X(\underset{+}{Y}, \underset{+}{q})
$$

where $L_{C}$ and $L_{I}$ are consumer and business loans as determinants of consumer durable expenditures $(C E)$ and investment $(I)$, respectively. $N X$ is net exports and $q$ is the real exchange rate (an increase in $q$ means real depreciation), $r$ is the real interest rate. Other variables have the usual meanings. The signs of partial derivatives are indicated underneath the variables. An increase in credit increases the relevant expenditure. Other signs reflect standard textbook assumptions. The reduced form of (1) gives the $I S$ curve:

$$
Y=A\left(\underset{-}{r}, L_{+}, L_{+}, \underset{+}{q}, \underset{+}{G}\right)
$$

\footnotetext{
${ }^{4}$ It is interesting to note how Keynes reasons as New-Keynesians do today in terms of imperfections impairing the "principles of the perfect market". From a Post-Keynesian stand point Wolfson (1996) provides a better explanation of the existence of "unsatisfied fringe of borrowers" or credit rationing.
} 
Other than the volume of consumer and business loans, this is the usual $I S$ curve. Thus, the curve is negatively sloped $\left(A_{r}<0\right)$ and shifts to the right with an increase in all other variables. In particular, a higher volume of credit shifts the $I S$ to the right. This formulation allows for the possible differential effects of consumer and business loans on effective demand to the extent that $\partial A / \partial L_{C} \neq \partial A / \partial L_{I}$.

Monetary policy in this setting works through the $\left(r, L_{C}\right.$ and $\left.L_{I}\right)$ variables in the $I S$ curve. We first consider the determination of the real rate of interest. As is well known central banks set a nominal policy interest rate. How this rate effects the real rate depends on the operating procedures of central banks. In this paper, we suppose an inflation targeting framework and the simplest possible nominal policy rate $(i)$ determination within this framework may be formulated as:

$$
i=i_{-1}+\left(\triangle p_{1}-\pi\right)
$$

where $\triangle p$ is inflation, $\pi$ is the target rate of inflation and subscripts show the period relative to the current period so that $\triangle p_{1}$ is the next period (expected) rate of inflation, and $i_{-1}$ is the policy rate in the previous period. Thus, the current interest rate is set at the last period rate augmented by any expected discrepancy between $\triangle p_{1}$ and the target rate, assuming a reaction coefficient of unity. Since markets use the same set of techniques conditional on the same information set to form expectations of $\triangle p_{1}$, and so guess what the Bank expects the expected inflation to be, they are usually correct in forecasting the path of the policy rate. This is how monetary policy is operative and becomes transparent under an inflation targeting regime. This simple formulation implies:

$$
r=i-\triangle p_{1}=i_{-1}-\pi
$$

So that the real interest rate is a predetermined variable, provided the rate of inflation has been following a path parallel to the target rate and is expected to do so in the immediate future. If the actual and the expected paths of inflation are systematically different from the target rate by a known and roughly constant amount, as is usually the case in many countries, then $\pi$ in this equation would be augmented by a corresponding amount and the real rate is still a predetermined variable. It must be noted that the real rate should, in fact, be defined as $\left(i_{m-1}-\pi\right), i_{m}$ is the market rate of interest relevant for economic calculations. The power of monetary policy resides in its ability to affect this market rate. In many formulations, as is here, no distinction is made between the two, and the determination of $i_{m}$ remains to be a critical aspect of the black box of monetary theory, to which no explanation is offered here.

Turning to loans, we first note that loans include but are not limited to bank loans. In an economy with some degree of formal markets, bank lending becomes the primary source and much of the credit channel literature is formulated on this source. Other sources of borrowing may become important in some cases such as trade credit, borrowing in informal markets or direct external borrowing by resident corporations. Moreover, what is important from the spending perspective is arguably liquidity defined as "... the ease with which perceptions of value can be turned into purchasing power. This definition captures two closely related notions of liquidity. One is "funding (cash) liquidity", or the ability to meet both current and future cash-flow and collateral needs... the other is "market liquidity", 
or the ability to trade an asset at short notice and with little impact on its price" (Borio \& Zhu, 2012, 244). "Higher liquidity weakens spending constraints" (Borio \& Zhu, 2012, 245) because just like borrowing provides liquidity, so does the ability to sell an existing asset "at short notice and with little impact on its price". The difference is that in the case of borrowing liabilities increase, while in the latter case assets fall, which may preferable in some cases. The value of these observations will become apparent when we consider capital inflows below.

Given that the market for bank credit is rationed with a pool of unsatisfied borrowers, as argued in the introduction, the prevailing (equilibrium) volume of bank loans is essentially supply determined with banks satisfying all creditworthy demand subject to limitations arising out of their own balance sheet constraints. The credit channel literature (for a detailed recent survey see Claessens and Köse (2017)) has made valuable contributions to our understanding to the effect that both the size of the pool and the ability of banks to lend may be affected by monetary policy. The balance sheet channel stresses how monetary policy may expand or contract the pool of borrowers through its effects on the balance sheets and income statements, including variables such as borrowers' net worth, cash flow and liquid assets. The bank lending channel focuses on the possible effect of monetary policy actions on the supply of loans by depository institutions. Borio and Zhu (2012) have proposed a possibly distinct channel called the "...'risk-taking channel' in the transmission mechanism, defined as the impact of changes in policy rates on either risk perceptions or risk-tolerance and hence on the degree of risk in the portfolios, on the pricing of assets, and on the price and non-price terms of the extension of funding" (Borio \& Zhu, 2012, 242). As lenders become more risk-tolerant, the liquidity of spending units increases.

It is perhaps worth re-emphasising the fact that the practices of central banking, the regulation of the banking industry and the transmission mechanism have country-specific attributes that are subject to change over time. In this paper, there is a broad emerging market setting in mind. Thus, for example, researchers of the CBRT (Central Bank of Turkey) formalise what they know from experience when they argue that reserve requirements are an effective policy instrument working through what they call a "liquidity channel" (Alper et al., 2016). When reserve requirements are increased, banks can obtain additional reserves from the central bank as the latter is committed, under the operating rules of inflation targeting, to supplying liquidity at pre-set conditions. "However, because central bank funding is collateralised, banks are left with fewer liquidity buffers to use against unexpected liquidity shocks. The marginal cost of borrowing from the central bank thus increases as the banks take into account the additional liquidity risk, which, in turn, leads to higher lending rates and/or a reduction in the pace of credit growth" (Alper et al., 2016, 18). In any event, they supply compelling evidence to the effect that "quantitative policies (such as reserve requirements) of the central bank affect the funding needs and the liquidity position of the banking system. The consequent changes in bank liquidity, in turn, have a significant impact on bank lending behaviour" (Alper et al. (2016, 49), the italicised bracket is added). It is clear that this reasoning is in accord with the definition of liquidity and "risk-taking" channel of Borio and Zhu (2012) mentioned above.

These arguments are formalised in the following functions for the (equilibrium) volume of loans $\left(L_{C}\right.$ and $\left.L_{I}\right)$, understood to be a broad indicator of the volume of financing or liquidity available to the respective unit: 


$$
L_{j}=f_{j}(i, \theta, \triangle F, z), j=C, I ; f_{j i}<0, f_{j \theta}<0, f_{j F}>0, f_{j z} ?
$$

where $i$ is the nominal (policy) interest rate, $\theta$ stands for "quantitative policies" of the central bank, such as reserve requirements, that affect the lending ability of banks; $\triangle F$ stands for gross capital inflows and $z$ is a parameter for exogenous shocks that may be positive or negative. A useful way to think about these functions is to understand them as referring to liquidity in the sense of Borio and Zhu (2012) as a determinant of spending constraints. The effects of monetary policy on the credit conditions or liquidity are captured by the negative partial derivatives with respect to the policy instruments. Capital inflows are considered in the next section. The formulation makes allowance for the fact that the magnitudes of partial derivatives are likely to be different for consumer and business loan volumes.

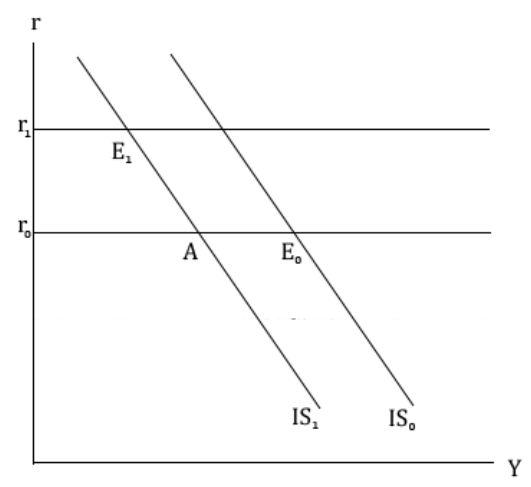

Figure 1: The IS Curve and the Credit Channel

Plugging (5) in (2) for $L_{C}$ and $L_{I}$, we see that policy rate changes have two distinct effects on the $I S$ curve:

$$
d Y / d i=(\partial A / \partial r)(d r / d i)+\left[\left(\partial A / \partial L_{I}\right) f_{I i}+\left(\partial A / \partial L_{C}\right) f_{C i}\right]<0
$$

where the second (square bracketed) negative term being the credit channel effect. The sign of the overall derivative follows from the signs of derivatives from (2) and (5) above. The credit channel effect is a shift factor in this formulation. The effect of an increase in the policy rate, resulting in a higher real rate according to (4), is shown in Figure 1 as a movement from $E_{0}$ to $E_{1}, E_{0}$ to $A$ being the credit channel effect and $A$ to $E_{1}$ being the traditional real rate effect reducing demand further.

Before considering the model further, let us see how it sheds light on the extreme conditions of the Great Financial Crisis (GFC) of 2007-09. Given the tranquil period of "great moderation" preceding the crisis with a low and stable inflation rate, (3) implies a constant nominal policy rate so that by (4), the real rate was constant and was expected to remain constant as shown by the horizontal line in Figure 2. So, the economy was at the initial equilibrium $E$ in Figure 2. For our purposes GFC meant a collapse of lending as well as a rush for liquidity because of widespread fears of bankruptcy, giving rise to a liquidity trap in which all units were holding onto cash. Under such conditions, both spending and lending decisions become totally insensitive to interest rates. Thus, not only that the $I S$ 
was shifted to the left to $I S_{1}$ in Figure 2, because of the collapse of lending, but it also became virtually vertical. Monetary policy in the form of reducing interest rates became totally ineffective, as the economy would be moving downwards along the virtually vertical $I S_{1}$ curve. Note that this has nothing to the with the "zero bound" argument. Even if there were enough margins by which policy rates could be reduced and resulted in lower market rates, the effect on output would be negligible. Moreover, in the absence of measures to contain the collapse of balance sheets, the $I S$ could continue to shift to the left. This left the policy of propping up balance sheets by direct purchases of illiquid asset as the only viable alternative, as the authorities with resonant memories of the great depression were quick to realise, thereby initially containing the pressure on the $I S$ to continue to shift to the left and eventually restoring lending and reviving spending. An expansionary fiscal policy is clearly fully effective in reviving effective demand under the conditions, as in fact was undertaken in most countries at least up until 2010.

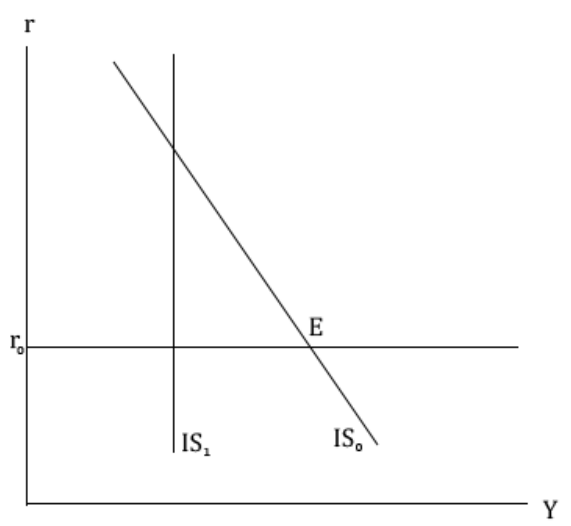

Figure 2: The Great Financial Crisis

\section{Capital Inflows}

In this section, a small economy under flexible rates and some degree of capital mobility is considered so that inflows depend on the interest rate differential. In the basic workhorse model of the open economy that is the basis of trained intuition of most of us, namely the Mundell-Fleming model, capital inflows are modelled in net terms and accommodate current account deficits/surpluses to maintain the balance of payments equilibrium at the world interest rate. They also result in changes in the value of the currency in the opposite direction both nominal and real terms, providing the linkage to the output determination. Here gross inflows are modelled. Borio and Disyatat (2015) provides an insightful analysis of gross inflows by delineating financing and resource constraints, the latter pertaining to the current account balance. Net capital inflows coincide with the current account balance. Gross inflows, on the other hand, are about financing constraints that we wish to model. Financing of production or expenditures is possible with gross flows without resulting in net inflows. Consider, for example, a resident bank accepting three months $F X$ deposit from a non-resident and lending it over the same maturity to an exporter. Once the original transaction is completed and the deposit is withdrawn, there is no net inflow, but the output 
is produced and exported, and income is realised in the process.

In general, the motives of residents in the analysis of capital inflows are neglected. If domestic assets are so valuable that, in a period of capital inflows, foreigners are coming to take advantage of them, why don't the current holders make use of the same advantage? Clearly, a resident unit would give up the ownership of an asset it's holding for foreign exchange or borrow in foreign exchange, only if it expects a better rate of return or a lower cost, relative to the domestic asset and domestic borrowing, respectively. A resident may sell some asset in exchange for foreign exchange and hoard it, for example, expecting a higher rate of return from holding foreign exchange relative to the asset over a longer maturity. This transaction increases the liquidity of the unit. If the proceeds find their way into the banking system in the form of foreign exchange deposit (as is possible in some countries) it increases the $F X$ liquidity of the banking system. If the bank sells the proceeds to the central bank, it has higher domestic currency liquidity. Likewise, a resident unit may be directly borrowing externally. Since no one would borrow funds to hold on to them, the proceeds must be used in financing some expenditure, buying an asset or paying back some debt, thereby increasing the liquidity of some other unit. All gross inflows probably do not end up financing some expenditure. However, they increase the liquidity of resident units and relive financing constraints. Moreover, the "risk-taking" channel, due to Borio and Zhu (2012), discussed above is particularly relevant in this context. If foreigners are taking positions in the country and are expected to do so for some time, this is a clear signal of improved risk perceptions or risk tolerance giving rise to favourable conditions in the bank loan market. It, thus, appears that the inclusion of changes in gross inflows $(\triangle F)$ in Equation (5) above is justified.

The responsiveness of inflows to interest rate differentials depends on the country in question and the buoyancy of world liquidity and the degree of "risk appetite" of the financial centres. The usual formulation of capital inflows as a function of the nominal interest differential is modified accordingly:

$$
\triangle F=\phi\left(i-i^{*}-\triangle e_{+1}\right)+u ; \phi \geq 0
$$

where $i^{*}$ is the foreign interest rate, $\triangle e_{+1}=$ one period ahead expected rate of depreciation of the domestic currency, and $\phi$ is a country-specific parameter showing the responsiveness of inflows to the interest rate differential in terms of foreign currency. The term " $u$ " stands for all other factors not captured by $\phi$. Note that $u$ can be positive, zero or negative so that with the same interest rate differential a country may be attracting more or less capital depending on the direction and the force of factors that affect the "risk appetite" of the creditors. With $\triangle F$ given by (7) the effect of a change in the policy rate on the $I S$ curve becomes, for a given expectation of the exchange rate depreciation:

$$
\begin{gathered}
d Y / d i=A_{r}(d r / d i)+\left[\left(\partial A / \partial L_{I}\right) f_{I i}+\left(\partial A / \partial L_{C}\right) f_{C i}\right]+ \\
{\left[\left(\partial A / \partial L_{I}\right) \phi f_{I F}+\left(\partial A / \partial L_{C}\right) \phi f_{C F}\right]}
\end{gathered}
$$

The third term in square brackets is the positive "capital inflow effects". The overall sign of the sum of the negative credit channel and positive capital inflows effects is indeterminate. Capital inflow effects tend to counteract the credit channel effects, thereby reducing the effectiveness of monetary policy considerably. Because while a tighter policy induces 
a contraction of liquidity through the credit channel effect as explained in the previous section, it enhances the liquidity of resident units to the extent that it's instrumental in increasing gross capital inflows. Monetary policy is less effective, the higher is $\phi$, because it induces more capital inflows for a given policy rate change. Under plausible conditions it is conceivable that a strong enough capital inflow effect is capable of totally offsetting the credit channel effect or even reversing it (the sum of square bracketed terms in (6b) becomes near zero or even positive) so that in terms of Figure 1 either the $I S$ stays at $I S_{0}$ or even shifts to the right following an increase in the policy rate.

This possibility is not a mere theoretical curiosum and has been a source of worry for the policymakers in emerging markets during periods of buoyant capital inflows. A recent IMF study takes on the issue:

"Emerging market policy makers ... see capital flows as leading to credit booms and an increase in output, which can only be offset by an increase in the policy rate. They point to a policy dilemma: while the direct effect of an increase in the rate is to limit the increase in output, it may lead to even higher capital inflows, and this second effect may dominate the first. The evidence appears to support the beliefs of policy makers: Capital inflows appear to be typically associated with appreciations, credit booms, and an increase in output. They also appear to play a major role in driving boom-bust cycles..." (Blanchard et al., 2017, 3).

They offer an explanation by introducing two types of domestic assets within a highly stylized portfolio balance model. The critical asset is what they call the non-bond assets, like foreign direct investment, domestic equities, and domestic bank liabilities. The rate of return on these assets, which they equate with the cost of financial intermediation or borrowing, "can be significantly affected by capital inflows" (Blanchard et al., 2017, 5). Thus, capital inflows, by reducing the rate of return on non-bond assets or borrowing may lead to "... a credit boom and an output increase, despite the appreciation" (Blanchard et al., 2017, 8). It is clear that this line of explanation is within the "external finance premium" paradigm and "darkens" the black box whereby the relation between the rate of return on non-bond assets and the cost of borrowing; that between the cost of borrowing and the "credit boom" and finally that between the boom and spending are left unexplained. This contrasts with the line of explanation offered here whereby (gross) capital inflows enhance the liquidity of resident units and result in higher spending.

\section{Completing the Model}

A reasonably encompassing model, requires the determination of price level and the exchange rate. The domestic price level $(P)$ is a weighted geometric average of the prices of domestically produced $\left(P_{d}\right)$ and imported goods $\left(E P^{*}=E\right.$, normalising the foreign price level $\left(P^{*}\right)$ at unity and $E$ is the nominal exchange rate),

$$
P=P_{d}^{a} E^{b}, \quad a+b=1
$$


Domestic prices are determined by a mark-up $(m)$ over unit cost, consisting of wage $(W)$ and imported input costs:

$$
P_{d}=(1+m)(W+E)
$$

where unit input requirements are assumed to be unity, to reduce notation. The real exchange rate is then:

$$
q=E / P_{d}
$$

with $d q / d E=(1+m) W / P_{d}^{2}>0$. It follows, from (8) that, lower case letters $(p, w, e)$ showing logarithms, the rate of inflation $(\triangle p=\triangle \ln P)$ can be written as:

$$
\triangle p=a s \triangle w+[a(1-s)+b] \triangle e=a s \triangle w+(1-a s) \triangle e
$$

where $s=W /(W+E)$ is the share of wages in unit cost of domestic output. This says that inflation is determined by the rate of wage inflation and the rate of depreciation according to their weights in the price level and the unit cost of domestic output. The usual assumptions in models for advanced economies are that $s=a=1$, so that inflation depends solely on wage inflation. The formulation in (8) is more representative of emerging markets, and many energy-importing advanced economies $(s<1)$. Moreover, $b=1-a$ cannot be assumed to be zero even in advanced economies given the volume of imports of labour intensive consumer goods from emerging economies.

Finally, short run movements of the exchange rate are governed by capital inflows:

$$
\triangle e=\pi-\gamma \triangle F, \gamma>0
$$

which in view of (7) can be thought of in more familiar terms:

$$
\triangle e=\pi-\gamma\left[\phi\left(i-i^{*}\right)+u\right]+\gamma \phi \triangle e_{+1}
$$

Thus, all factors that increase capital inflows lead to an appreciation of the currency in the current period. The inclusion of $\pi$ in (11) follows from (10) which implies that in a steady inflationary equilibrium we must have $\pi=\Delta p=\Delta w=\triangle e$.

\begin{tabular}{lr}
\multicolumn{2}{c}{ Table 1: Model Equations } \\
\hline$Y=A\left(r, L_{C}, L_{I}, q, G\right)$ \\
$q=E / P_{d}$
\end{tabular}


The model equations are shown in Table 1. There are two blocks, the second (last four equations) being the financial block, where only "rates" are determined. The inflation equation is in this block because it determines a rate. Note that this block is independent of the first (the output block). This is a property that we may call the Keynesian dichotomy (Pasinetti, 1979, 44-45). In the financial block equilibrium is compatible with any constant rate of inflation/depreciation so long as $\triangle F=0$. That is, there is a "rate indeterminacy" and the role of monetary policy is to determine and enforce an "anchor" for the "rates". In our setting the anchor is the target rate of inflation, $\pi$. Given this anchor we can define a steady equilibrium with $\triangle p=\pi=E\left(\triangle p_{1}\right)=\triangle e=\Delta e_{+1}$. Whether this state is attainable is an altogether different issue depending on the ability of the central bank to enforce the anchor. When the state is attained with $\triangle F=0$ and $\triangle e_{+1}=\pi$, we have from (7), that

$$
i=i^{*}+\pi-u / \phi
$$

This shows what the policy interest rate should be to be consistent with the steady state. It is seen that unfavourable external conditions $(u<0$, lower $\phi)$ will require a higher rate. In short, central banks can only target and determine a "rate" through the instrument they control, which is also a rate. Determining the short-term interest rate on its own does not make sense unless it's tied to some target, such as some monetary aggregate, the nominal exchange rate or a target inflation rate. In any event, the art of central banking is to devise a system of rules, regulations and operating procedures to define and establish a target rate and to steer the markets towards an equilibrium based on this target.

When an equilibrium in "rates" in the financial block is established, the real rate and the loan aggregates are also determined from equations (4) and (5), respectively. But this is not enough to solve the output block because the levels of $P, E$ and $W$ are not known. In fact, we need only to know the levels of the wage and the exchange rates since the price level depends on them. This is the nominal indeterminacy, or the nominal anchor, problem of macro models. This problem is distinct from the "rate" indeterminacy just mentioned, which is in the realm of monetary policy. Monetary policy cannot determine levels, but only rates and there is no macro model that can determine the levels of nominal variables without an "anchor", that is a nominal variable whose value is given from outside the system that can be used to solve for the remaining nominal variables. In the closed economy neoclassical model, as is well known, the anchor is the nominal money supply, which is supposed to be controlled by the central bank. Since all real variables are determined in the auction market, equilibrium $W / P$ and $M / P$ are known, so that if $M$ is given, one knows $P$ and $W \cdot{ }^{5}$ In an open economy, the real exchange rate $=E P^{*} / P$ is known from the goods market equilibrium, so that the nominal exchange rate can be determined, provided $P^{*}$ is also known as the second anchor. A sort of Tinbergen's rule applies here and we need as many nominal anchors as there are independent nominal variables.

Such practices are not open to us. Instead, the nominal anchor is provided by the immediate past:

$$
\begin{aligned}
& W=W_{-1}\left[1+\alpha(t) \triangle p_{-1}\right] \\
& E=E_{-1}
\end{aligned}
$$

\footnotetext{
${ }^{5}$ This entails a logical inconsistency in an inflation targeting framework because it requires the determination of both the price and the quantity of money by the central bank, which is not possible.
} 
For the wage equation this implies, defining $\Delta w=\left(W / W_{-1}\right)-1$ :

$$
\triangle w=\alpha(t) \triangle p_{-1}
$$

So that we are supposing that the wage rate is adjusted in proportion to past inflation. There is no adjustment in the case of the nominal exchange rate in (12b), because it is an asset price whose rate of change is determined in the financial block by (11) so that $E_{-1}$ includes all changes expected to take place in the current period. The nominal wage rate, on the other hand, is updated in each period on the basis of past inflation by a time-specific $\alpha$ parameter. In the Post-Keynesian literature, the adjustment rate $(\alpha)$ is typically thought to depend on the balance of powers in the struggle for distributive shares, an idea that goes back at least to Rowthorn (1977). The latter, in turn, could depend on the past movements of the real wage rate and the growth rate of output and productivity. If real wages have been stagnant or falling for some time $(\alpha<1)$, there may be a backlash at a point in time so that $\alpha(t)>1$ may be possible over a period. Times of rapid growth may give workers an upper hand in wage bargains. Expectations of accelerating inflation may also be a factor that can be incorporated by setting $\alpha(t)>1$. However, on average we may suppose, and this is also the case suitable for analytic work, that $\alpha \leq 1$.

To those who think in terms of the Walrasian auction paradigm, equations in (12) introduce an ad-hoc price rigidity. In the auction world, everything is determined simultaneously, whereas we are considering a logico-temporally ordered the world. For output to be produced workers must be hired and intermediate inputs must be purchased. But prices must be known so that appropriate payments can be made to hire workers and purchase intermediate inputs. Workers don't work on the promise of being paid an amount to be determined later. The same is true of payments for intermediate inputs. Contracts must be concluded in nominal terms so that all parties know what they are going to get and pay. There is no theory that can be used to determine what the dollar worth of an hour's work, or the dollar worth of a euro, say, should be. What makes economic calculations possible in any period is the simple fact that units start with a known value inherited from the past. Thus, the formulation far from being ad-hoc is in accord with the nature of nominal determination and is a necessary step to enforce the Post-Keynesian logico-temporal ordering of production and distribution on a simultaneous equation system. Simultaneous equation systems fit in naturally with the auction paradigm, where everything depends on everything else. In a Post-Keynesian setting their use must be complemented with an appropriate lag-lead structure to make them conformable as much as possible with the order of things as contemplated by the Post-Keynesians.

The same reasoning goes with the Keynesian dichotomy mentioned above. A term capturing policy response to output deviations from, say, some trend value believed to be corresponding to full capacity output, may be included in the interest rule in (3). This would make the two blocks simultaneous as in the orthodox models. However, the simple fact is that authorities cannot observe deviations of output from trend until they occur, by which time the output has already been produced. Hence, policy and output cannot interact contemporaneously so that either a lagged value or the expected future value of the deviation must be included in the policy rule. While the principle is widely recognised in empirical work, such as in ordering of equations in $V A R$ systems, New-Keynesian theoretical models routinely violate it as shown in the appendix. Likewise, the output block 
may affect the inflation equation through wage determination. But the effect will not be contemporaneous given our rule for wage rate determination. In short, what matters is that there is no contemporaneous feedback from output to the financial block 6 . The specifics, and no doubt deficiencies, of the current formulation as in Table 1 should not detract from the significance of these principles. Keynesian dichotomy, addressing the nominal indeterminacy as opposed to "rate indeterminacy", and an appropriate lead-lag structure accounting for the logico-temporal ordering of production and distribution are interrelated essential features of a Post-Keynesian model.

The solution to the financial block together with (12a-12c) will suffice to determine the position of the $I S$ curve and output. We have to note that the financial block does not admit a closed-form solution by way of solving the implied system of difference equations. This is because the apparently reasonable and simple lead-lag structure in the equations of the block does not result in a convenient first order system (the appendix shows how the same problem would arise once an appropriate lead/lag structure is introduced within the New-Keynesian context). However, the model does permit a sequential solution generating a meaningful transitional dynamic, at least for the initial phases of the adjustment from one equilibrium to the other. First note, that in equilibrium $\triangle F=0$ and $\triangle p=\pi=\triangle p_{1}=\triangle e=\triangle e_{+1}$ at the steady state equilibrium. On the other hand, in view of (12a-12c), we can write:

$$
\triangle p=a s \alpha \triangle p_{-1}+(1-a s) \triangle e_{-1}
$$

so that inflation is a pre-determined variable in any period. This also means that

$$
\triangle p_{1}=a s \alpha \triangle p+(1-a s) \triangle e
$$

so that (expected) inflation is fully determined once current inflation and exchange rate changes are observed. Therefore, from (3) we see that policy will respond to current inflation and depreciation. Policy responding contemporaneously to the inflation and the exchange rate depreciation follows from the model and may be justified on the basis that these variables can be observed or can be forecast accurately within the period. Finally, from (7) and (11) the rate of depreciation responds to current monetary policy, given expectations of future inflows (depreciations). The most likely cause of any instability in the model is the possibility of a runaway depreciation (capital outflow) that does not respond to policy (higher interest rate). Excepting such crisis periods, we may suppose the system to be stable within bounds of the normal course of the economy.

\subsection{An Example}

As an illustration, effects of a negative shock to capital inflows $(u<0)$ is shown in Figure 3. Initially, $\triangle F=0$ and $i=i^{*}+\pi$ as determined from (7a) with $u=0$ as shown in the first panel $(Q 1)$. The numbers next to functions in Figure 3 refer to equation numbers. In other panels points labelled with $\pi$ correspond to the initial steady equilibrium $\triangle p=\pi=\triangle p_{1}=\triangle e$. In particular, in panel $(Q 4)$ with expected and target inflation rates equal we have $i=i_{-1}(\triangle i=0)$.

\footnotetext{
6 The $L M$ curve is a major detriment to appropriate Post-Keynesian modelling because of the simultaneity it introduces between the two blocks of the model.
} 
Because of the negative shock, the (7) line shifts down to the right in panel (Q1) resulting in capital outflows at the initial interest parity as shown at the point $A$. Points $A$ in other panels correspond to a new constellation of values. Capital outflows trigger a higher rate of depreciation given by (11) in the second panel. As a result, expected inflation goes up by (1-as) $\triangle e$ as shown in the third (Q3) panel of Figure 3. The resulting discrepancy between the expected inflation and the target rate triggers the Bank's response in the last panel $(Q 4)$. Thus, in the next period, the interest rate is higher partially reversing the outflows. Capital outflows would be fully reversed at $\mathrm{E}$ in panel $(Q 1)$ with a higher rate $i=i^{*}+\pi-u / \phi$ reflecting the unfavourable world conditions.

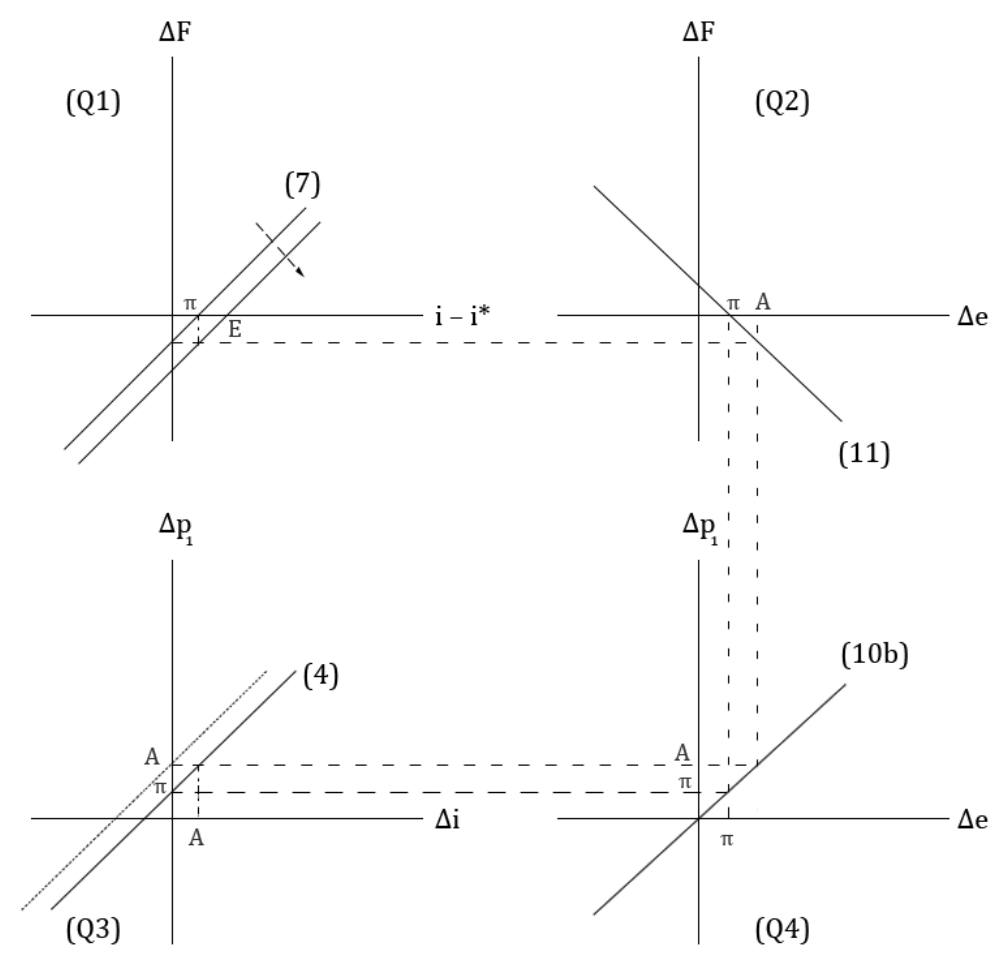

Figure 3: Effects of an external shock to capital flows

The restoration of equilibrium at a higher interest rate at $E$ in $(Q 1)$ of Figure 3, may be relatively fast as the Bank is likely to be able to make the necessary adjustment to the rate with reasonable accuracy within a short period. In particular, suppose that in just one period the interest rate is restored to the point $E$ in panel $(Q 1)$ of Figure 3 and there are no further external pressures. It is then possible that there is a one-off increase in the current exchange rate and the next period price level. The real wage would fall, however, when the price level increases and may trigger an adjustment as defined in (12a) in the following period. Because, as we argue shortly, there will be some unemployment in the process, the change in the exchange rate is one-off, the target inflation rate remains the same and because we are in a broad emerging market setting where wage adjustments tend to be much slower and come with a long lag, we shall underplay this source of possible inflation dynamics in this presentation. We see then that the same $\triangle p=\triangle p_{1}=\triangle e$ "rate equilibrium" can 
be compatible with a higher nominal interest rate resulting from the unfavourable world conditions.

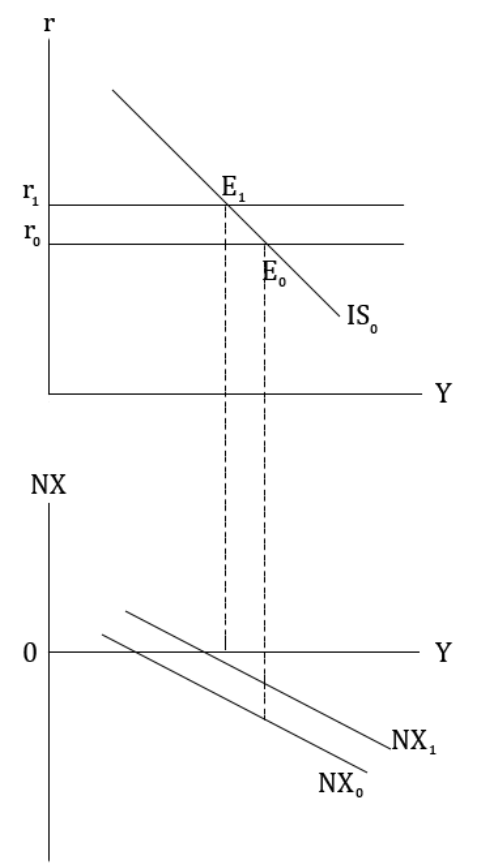

Figure 4: Output and trade balance effects of an external shock to capital flows

What happens in the output market depends on the balance between two opposite forces. On the one hand, there is some real depreciation resulting in higher demand for domestic output shifting the $I S$ curve to the right. On the other, there is some tightening of liquidity conditions and loan volumes in the economy due to the capital outflows and higher interest rates (see Equation (6b)). The point is that although outflows are reversed with a higher interest rate, there has been some outflow which means that some credit lines were not renewed, and/or domestic assets were sold. Because of tighter liquidity, the $I S$ would shift to the left. These effects are closely related in that if the capital outflows are strong, the capital outflow effect is stronger; but it also means that depreciation is higher resulting in a stronger real depreciation effect. The required monetary tightening would also be stronger, the stronger are the outflows. On balance, given the short-lived nature of the outflows, we may suppose the three (credit channel, capital inflow and real depreciation) effects to cancel out and the $I S$ curve stays approximately put at $I S_{0}$ in Figure 4 . This mean that there is only the output reduction due to traditional real interest rate effect along the $I S_{0}$ curve (equilibrium moves from $E_{0}$ to $E_{1}$ ) and the trade balance (in terms of domestic output, $N X$, as defined in Equation (1) above) improves both due to lower output and real depreciation as shown in the bottom panel of Figure 4 (the shift to $N X_{1}$ is due to real depreciation). If credit and capital outflows effects outweigh, the $I S$ would shift to the left, resulting in higher loss of output and a stronger recovery of the trade balance. 
Another possible outcome is that it takes several periods to reach the point $E$ in panel (Q1) of Figure 3 so that outflows and depreciation continue for some time. It is not uncommon that the central bank implicitly accepts this higher rate of depreciation and resulting inflation. That is, the Bank adjusts the policy rate gradually just enough to contain the outflow. This can be due to unfavourable world conditions (low $\phi$ ) requiring too sharp an increase in the policy rate with an uncertain effect. Alternatively, the Bank implicitly takes into account the dislike of the political authorities of higher rates. In this case, while the official target remains at $\pi$, the actual target becomes $A$ so that in panel $(Q 4)$ of Figure 3, the relation defined by Equation (3) effectively shifts to the left (shown by the broken line) accommodating this higher expected rate. The interest rate is higher so that there are no longer outflows, but the new equilibrium is established at a higher rate of inflation and depreciation for some time to come. The effect on output is like above, except that the capital outflows effect may be stronger, shifting the $I S$ to the left, resulting in a higher loss of output and larger swing in the trade balance. The wage dynamics is harder to ignore in this case and there will eventually be an adjustment. Since there is no closed-form solution for the transitional dynamics over a longer period, a simulation could be one way to provide some answers. On the other hand, since answers so provided assume that nothing else changes over a long period of time, and it is usually the case that other significant changes do take place, in most cases, it may suffice to have a description of the sequence of events over the initial few periods as is done here.

Yet another outcome is possible if the central bank is determined to enforce the target rate of inflation. This requires the interest rate to increase beyond the point $E$ in panel (Q1) Figure 3. The tightening signals to the markets the resolve of the Bank in achieving its targets, which is usually considered to be an additional positive factor for the country. The initial nominal depreciation means that the entry level of the exchange rate is high and there is the expectation of nominal appreciation given the tightening, implying well above average prospective rates of return in terms of foreign currency. The country, thus, becomes a very attractive target for inflows. Hence, assuming that the initial unfavourable risk perceptions dissipate, the country may come to experience a strong influx of capital generating a strong capital inflows effects resulting in an expansion ( $I S$ shifting to the right in Figure 4). It will be instrumental, nonetheless, in reversing the inflationary momentum because of the appreciation it generates, while the policy-makers would believe, based on the three equation New-Keynesian model, that inflation could be controlled because the tightening reduced the "output gap" 7 . The trade balance would deteriorate both because of the appreciation and the expansionary effects of the capital inflows.

\section{Conclusions}

The credit channel literature implicitly relies on the fact that capital spending depends on financing and that credit is the main form of financing. The mainstream model tries to avoid this implication by recourse to artificial concepts and variables such as the "external

\footnotetext{
7 The New-Keynesian model is prone to an inconsistency in explaining the monetary policy, inflation control nexus. If in response to a monetary tightening, inflation falls because of reduced "output gap", then the current account must improve, given that reduced "output gap" should mean a fall in absorption relative to income. On the contrary, higher interest rates, appreciating currency and a widening current account balance are often observed together as described here, and as recognised in (Blanchard et al., 2017)
} 
finance" premium. We, by contrast, have explicitly modelled capital expenditures as a function of the credit volume along with other relevant variables. This formulation has roots in the Post-Keynesian logico-temporal ordering of production and the realisation of income. Production starts with producers going into debt to pay for wages and materials. At this stage, wage incomes are realised and distributed. The second stage of debt or financing is required to sell the output of capital goods and realise non-wage income. The inclusion of credit in expenditure functions corresponds to this idea and results in a simple income determination model making the roles of credit and monetary policy transparent.

A financial block is required for the determination of the interest rate, asset prices and credit aggregates that affect spending decisions. This block is in the realm of monetary policy. At this stage, important principles of Post-Keynesian macro modelling are stressed. The first principle is the Keynesian dichotomy, whereby there is no contemporaneous feedback from the output block to the financial block. Second, monetary policy can only control a rate, the policy rate of interest, and therefore can only affect rates. The art of central banking consists in establishing an equilibrium in rates by manipulating the policy instrument with a view to achieving a target rate of its choice. The model of this paper is the simplest possible framework compatible with the currently dominant framework of inflation targeting, where the target rate is the (expected) inflation rate. In general, the rate equilibrium is not unique, in that the same policy rate may be compatible with different constellations of other rates depending on the non-policy determinants of the target rate. An example would be the strength of capital inflows affecting the rate of currency depreciation, which in turn is a determinant of the rate of inflation.

The fact that monetary policy can only determine rates leaves the levels of critical nominal variables such as the wage rate and the exchange rate undetermined, and there is no theory to determine them. These are required for the solution of the overall model. This is the nominal anchor problem. The third principle of Post-Keynesian modelling, it is argued, is that nominal anchors for the wage rate and the exchange rate are to be found in the immediate past as dictated by the logico-temporal timing of production. Associated with these principles is the necessity of imposing an appropriate lead-lag structure on the simultaneous equations defining the model.

The model in this paper, despite its extremely simple structure, does not admit an explicit solution. But it can be interpreted sequentially to provide a reasonable account of events based on comparative analysis. Short of simulating the model based on parameter estimates, we can only provide an account of a likely sequence of events in the initial periods of adjustment as a full account becomes intractable given the multitude of responses. Moreover, as illustrated by the account of the effects of an external shock to capital inflows, several plausible outcomes resulting from the same change are possible, depending on the nature of the change and the policy responses. It appears that seeking to specify models that admit unique closed-form solutions may result in failing to identify the wealth of possible responses to changes. This, in turn, would mean an incomplete understanding of the nature of the economies we study. 


\section{Appendices}

Equations of a typical New-Keynesian model as taken from Galí (2008, 49-50) are:

$$
\begin{aligned}
\pi_{t} & =\beta E_{t}\left\{\pi_{t+1}\right\}+\kappa Z_{t} \\
Z_{t} & =-1 / \sigma\left(i_{t}-E_{t}\left\{\pi_{t+1}\right\}-r_{t}^{n}\right)+E_{t}\left\{Z_{t+1}\right\} \\
i_{t} & =\rho+\phi_{\pi} \pi_{t}+\phi_{y} Z_{t}+V_{t}
\end{aligned}
$$

where we have only changed the notation for the output gap to $Z_{t}$. Here $v$ is the exogenous component of the policy rule. It clearly violates the principle that policy makers cannot observe and act on a variable at the same time. This system can only make sense, as is implicitly contemplated, if a central bank representative takes part in the auction process where households meet. This means that apart from vt the policy rate is just like any other price determined endogenously in the auction. The Bank has the privilege of being able to change the price at will, presumably, by virtue of having the monopoly of cash creation. Leaving the arbitrariness of the set up aside, the system results in a first order system of the type

$$
\left[\frac{Z_{t}}{\pi_{t}}\right]=A\left[\frac{E_{t}\left(Z_{t+1}\right)}{E_{t}\left(\pi_{t+1}\right)}\right]+B
$$

where $A$ is a 2x2 matrix of coefficients of the reduced form and $B$ is a vector of exogenous variables. We know how to solve this system. The model is then used to simulate the effects of a shock to " $v_{t}$ ". But, suppose more appropriately, that central bank officers are not allowed in the auction rooms. Instead, they can only declare a number " $i_{t}$ " to the auctioneer and the auction results in $\pi_{t}$ and $Z_{t}$ from (21) and (22). The central bank then observes and reacts according to

$$
i_{t+1}=\rho+\phi_{p i} \pi_{t}+\phi_{y} Z_{t}+V_{t}
$$

which is the input for the next auction. The system (21), (22) and (23a) cannot be reduced to a convenient first order system as in (24). If $\rho$, which is unknown, is replaced with $i_{t}$ in (23a), matters will become even more complicated. 


\section{References}

Alper, K., Binici, M., Demiralp, S., Kara, H., \& Özlü, P. (2016). Reserve Requirements, Liquidity Risk, and Bank Lending Behavior (Working Paper Series No. 1612). Koç University-TÜSIAD Economic Research Forum (ERF). http://hdl.handle.net/ $10419 / 166736$.

Bernanke, B. S., \& Gertler, M. (1995). Inside the Black Box: The Credit Channel of Monetary Policy Transmission. Journal of Economic Perspectives, 9(4), 27-48. doi:10.1257/jep.9.4.27

Blanchard, O., Ostry, J. D., Ghosh, A. R., \& Chamon, M. (2017). Are Capital Inflows Expansionary or Contractionary? Theory, Policy Implications, and Some Evidence. IMF Economic Review, 3(65), 563-585. doi:10.1057/s41308-017-0039-z

Borio, C., \& Disyatat, P. (2015). Capital Flows and the Current Account: Taking Financing (more) Seriously (Working Papers No. 525). Bank for International Settlements (BIS). https://www.bis.org/publ/work525.pdf.

Borio, C., \& Zhu, H. (2012). Capital Regulation, Risk-taking and Monetary Policy: A Missing Link in the Transmission Mechanism? Journal of Financial Stability, 8(4), 236-251. doi:10.1016/j.jfs.2011.12.00

Claessens, S., \& Köse, M. A. (2017). Macroeconomic Implications of Financial Imperfections: Survey (Policy Research Working Paper No. 8260). World Bank, Washington, DC. World Bank. http://hdl.handle.net/10986/28921.

Galí, J. (2008). Monetary Policy, Inflation, and the Business Cycle, An Introduction to the New Keynesian Framework. Princeton University Press. Princeton, New Jersey.

Keynes, J. M. (1930). Treatise on Money, Volume I: The Pure Theory of Money. MacMillan and Co. Limited. St. Martin's Street, London. Retrieved from https://ia801608.us.archive.org/27/items/in.ernet.dli.2015 $.45480 / 2015.45480$. A-Treatise-On-Money--Vol1.pdf

Keynes, J. M. (1937). The "ex-ante" Theory of the Rate of Interest. The Economic Journal, 47(188), 663-669. doi:10.2307/2225323

Lavoie, M. (1984). The Endogenous Flow of Credit and the Post Keynesian Theory of Money. Journal of Economic Issues, 18(3), 771-797. doi:10.1080/00213624.1984.11504274

Pasinetti, L. L. (1979). Growth and Income Distribution: Essays in Economic Theory. Cambridge University Press.

Rochon, L.-P., \& Rossi, S. (2007). Central Banking and Post-Keynesian Economics. Review of Political Economy, 19(4), 539-554. doi:10.1080/09538250701622402

Rowthorn, R. E. (1977). Conflict, Inflation and Money. Cambridge Journal of Economics, 1(3), 215-239. doi:10.1093/oxfordjournals.cje.a035360

Wolfson, M. H. (1996). A Post Keynesian Theory of Credit Rationing. Journal of Post Keynesian Economics, 18(3), 443-470. doi:10.1080/01603477.1996.11490081 